\title{
A compendium of developmental gene expression in Lake Malawi cichlid fishes
}

\section{R. F. Bloomquist \\ T. E. Fowler \\ J. B. Sylvester \\ R. J. Miro \\ J. T. Streelman}

\section{Video Abstract}

Keywords: Cichlid fishes, Evolution of gene expression, Lake Malawi, Developmental pathways

Posted Date: November 20th, 2020

DOI: https://doi.org/10.21203/rs.3.rs-112264/v1

License: (9) This work is licensed under a Creative Commons Attribution 4.0 International License. Read Full License 


\section{Abstract}

Rapid evolutionary radiations can produce large numbers of species in relatively short time scales and result in myriad forms. Studying these bursts of speciation provides important insights into the accumulation of biological diversity and the evolution of physical traits. Lake Malawi cichlids represent an impressive example of one such radiation and provide an ideal system for understanding the genetic and molecular pathways underlying trait divergence. Physical differences between organisms are often the result of variation in gene expression, which can occur in spatial, temporal, or quantitative space. In other words, _where_, _when_, and _how much_t the expression of genes change, can have pronounced physical effects. Focusing on the _where_, a team of researchers at the Georgia Institute of Technology charted patterns of expression from the jaws to the tails of cichlids. Using a method called_in situ_ hybridization, the team developed labeled molecular probes for approximately 160 genes in two species. However, because of the modest amount of DNA sequence changes across this assemblage of fish, the probes developed here will be useful in hundreds of species. The result of these efforts is a detailed collection of spatial gene expression data across early development of cichlids. Included in this are examples of expression patterns conserved with many other animals, as well as patterns that had previously never been assayed at these particular tissues and times. These data provide an important resource for researchers attempting to understand the relationship between development and evolution and may provide important clues about the evolution of gene regulation. 